\title{
RED BLOOD INDICES, PLATELET COUNT AND TRANSFERRIN LEVELS IN CELIAC PATIENTS WITH AND WITHOUT TYPE I DIABETES MELLITUS IN HYDERABAD, SINDH, PAKISTAN
}

\author{
Komal Siddiqui', Muhammad Rafiq', Muhammad Aqeel Bhutto', Arsalan Ahmad Uqaili ${ }^{2 凶}$
}

\section{ABSTRACT}

OBJECTIVE: To analyze the hematological manifestations among celiac disease (CD) and CD with type-I diabetes mellitus (TIDM) children to aid in differential diagnosis and management of disease.

METHODS: This study was conducted at Institute of Biotechnology and Genetic Engineering, University of Sindh, Jamshoro, Pakistan. CD pediatric patients were diagnosed through serological or intestinal biopsy. The individuals were divided into 5 groups (35 each); Control (A), diagnosed cases of CD (B), individuals affected with celiac-like indications (C), TIDM patients with celiaclike symptoms (D) and TIDM patients (E).

RESULTS: Mean age of 175 participants was $9.5 \pm 1.2$ years. Mean hemoglobin level $(\mathrm{mg} / \mathrm{dl})$ was $9.1 \pm \mathrm{I} .1,9.03 \pm \mathrm{I} .4,8.64 \pm \mathrm{I} .2$ and $\mathrm{II} .7 \pm \mathrm{I} .3$ in group-B, group-C, group-D and group-E respectively as compared to $13.02 \pm 1.5$ in Group-A $(\mathrm{p}<0.00 \mathrm{I})$. Mean corpuscular volume (MCV) [fl] was 64.I \pm 5.4 , $68.5 \pm 7.8,57.6 \pm 6.0$ and $69.4 \pm 4.4$ in group-B, group-C, group-D and group-E respectively as compared to $84.4 \pm 7.3$ in Group-A $(p<0.001)$. Mean corpuscular hemoglobin (MCH) [group-B: $24.1 \mathrm{pg}$, group-C: $25.5 \mathrm{pg}$, group-D: 24.6pg] and mean corpuscular hemoglobin concentration (MCHC) [group-B: $29.3 \mathrm{~g} / \mathrm{dl}$, group-C: $277.9 \mathrm{~g} / \mathrm{dl}$, group-D: $31.5 \mathrm{~g} / \mathrm{dl}]$ were decreased among all celiac affected cases. For group-E the hemoglobin, $M C V$ and $M C H C$ were in the normal ranges. Platelet Count (cells/ul) was $689 \pm 178 \times 10^{3}, 702 \pm 141 \times 10^{3}$, $518 \pm 124 \times 10^{3}$ and $529 \pm 101 \times 10^{3}$ in group-B, group-C, group-D \& group-E respectively as compared to $326 \pm 98 \times 10^{3}$ in group $A(p<0.01)$. Mean Transferrin levels $(\mathrm{mg} / \mathrm{dl})$ were $4 \mathrm{Il} .5 \pm 24.8 ; 387.7 \pm 22.4 ; 406.4 \pm 21.4$ \& $368.8 \pm 22.0$ in group-B, group-C, group-D and group-E and $271 . I \pm 39.1$ in group-A $(\mathrm{p}<0.0 \mathrm{I})$.

CONCLUSION: Hematological anomalies; like anemia and thrombocytosis are frequently present in mismanaged and late diagnosed $C D$ children.

KEY WORDS: Celiac disease (MeSH); Anemia, Iron-Deficiency (MeSH); Erythrocyte Indices (MeSH); Blood Platelets (MeSH); Thrombocytosis (MeSH); Diabetes Mellitus, Type I (MeSH).

THIS ARTICLE MAY BE CITED AS: Siddiqui K, Rafiq M, Bhutto A, Uqaili AA. Red blood indices, platelet count and transferrin levels in celiac patients with and without type I diabetes mellitus in Hyderabad, Sindh, Pakistan. Khyber Med Univ J 2020;13(I):25-9. DOI: https://doi.org//0.35845/kmuj. 2021.20553.

\section{INTRODUCTION}

$G$ lobally, about I\% of adult population is affected with Celiac disease (CD). It is also known as glutensensitive enteropathy, or non-tropical sprue.' It is genetic autoimmune disorder in which mucosal membrane of small intestine becomes hypersensitive to prolamins and glutelins; the polypeptides found in wheat, rye and barley. Due to which the enterocyte lining in intestine is damaged, consequently leading to digestive problems and poor absorption of nutrients. ${ }^{2} \mathrm{CD}$ can be asymptomatic or symptomatic with severe malnutrition giving rise to many complications; like anemia, ulcers, diarrhea, fatigue, late puberty and osteoporosis. ${ }^{3}$ It is common food related disorder in western
I: Institute of Biotechnology and Genetic Engineering, University of Sindh, Jamshoro, Pakistan.

2: Department of Physiology, Liaquat University of Medical and Health Sciences, Jamshoro, Pakistan

Email凶:arsalanuqaili@gmail.com

Cell \# + 92-333275570I

Date Submitted: July 01, 2020

Date Revised: February 04, 202।

Date Accepted: February 25, 202।

populations. ${ }^{4}$ It seems to be a common disorder among Pakistanis and it affects children to adults. However, there is no data regarding its prevalence. ${ }^{5}$ The high probability of occurrence of $C D$ ( $515 \%)$ is found in first and seconddegree relatives of the affected individuals. Besides this, other vulnerable individuals are those suffering with other autoimmune disorders, e.g., thyroiditis, type I diabetes mellitus (TIDM), and Down syndrome. ${ }^{6}$ Hematologic misbalance (84\%) has been described in $C D$ patients, in considerable frequency, ever since decades ago. ${ }^{7}$ The main obstacle is the misdiagnosis of $C D$, which paves the way to chronic and unresponsive irondeficiency anemia. Hematologic evaluation can be a helpful adjunct and prognostic marker for patients with $C D$, since it is difficult to make a diagnosis accurately due to its varied clinical presentations. Hematologic features of $C D$ are well described in the guidelines of the British Society of Gastroenterology, American College of Gastroenterology, and European Society for Pediatric Gastroenterology, Hepatology, and nutrition. 8 Although the guidelines cover a wide range of complications, yet numerous other deficiencies have been documented. Such as; insufficient folate causing megaloblastic anemia, irondeficiency anemia (IDA), vitamin $B_{12}$ deficiency and coagulopathy product of vitamin K deficiency. ${ }^{10}$ The most common clinical symptom is IDA, which could aid as an extra-intestinal diagnostic tool for CD screening. About 3.2\% of patients 
TABLE I: HEMATOLOGICAL MANIFESTATIONS AMONG DIFFERENT GROUPS $(\mathrm{N}=175)$

\begin{tabular}{|c|c|c|c|c|}
\hline Blood Parameters & Groups & Mean士S.D & F-Value & P-Value \\
\hline \multirow{5}{*}{$\begin{array}{l}\text { Hemoglobin levels } \\
(\mathrm{mg} / \mathrm{dl})\end{array}$} & A & $13.02 \pm 1.5$ & \multirow{5}{*}{20.88} & \multirow{5}{*}{0.0001} \\
\hline & $B$ & $9.1 \pm 1.1$ & & \\
\hline & C & $9.03 \pm 1.4$ & & \\
\hline & $\mathrm{D}$ & $8.64 \pm 1.2$ & & \\
\hline & $E$ & $11.7 \pm 1.3$ & & \\
\hline \multirow{5}{*}{$\begin{array}{l}\text { Mean corpuscular volume } \\
{[\mathrm{MCV}]} \\
\text { (fl) }\end{array}$} & $A$ & $84.4 \pm 7.3$ & \multirow{5}{*}{24.23} & \multirow{5}{*}{$0.000 \mathrm{I}$} \\
\hline & $\mathrm{B}$ & $64.1 \pm 5.4$ & & \\
\hline & C & $68.5 \pm 7.8$ & & \\
\hline & $\mathrm{D}$ & $57.6 \pm 6.0$ & & \\
\hline & $\mathrm{E}$ & $69.4 \pm 4.4$ & & \\
\hline \multirow{5}{*}{$\begin{array}{l}\text { Mean Corpuscular } \\
\text { Hemoglobin }[\mathrm{MCH}] \\
\text { (pg) }\end{array}$} & A & $32.4 \pm 1.3$ & \multirow{5}{*}{45.23} & \multirow{5}{*}{0.0001} \\
\hline & B & $24.1 \pm 1.4$ & & \\
\hline & C & $25.5 \pm 1.8$ & & \\
\hline & $D$ & $24.6 \pm 0.8$ & & \\
\hline & $E$ & $26.4 \pm 0.7$ & & \\
\hline \multirow{5}{*}{$\begin{array}{l}\text { Mean Corpuscular } \\
\text { Hemoglobin } \\
\text { Concentration }[\mathrm{MCHC}] \\
(\mathrm{g} / \mathrm{dl})\end{array}$} & $\mathrm{A}$ & $34.1 \pm 0.6$ & \multirow{5}{*}{64.78} & \multirow{5}{*}{0.0001} \\
\hline & $\mathrm{B}$ & $29.3 \pm 0.9$ & & \\
\hline & C & $27.9 \pm 1.1$ & & \\
\hline & $\mathrm{D}$ & $315 \pm 0.8$ & & \\
\hline & $\mathrm{E}$ & $30.2 \pm 0.3$ & & \\
\hline \multirow{5}{*}{$\begin{array}{l}\text { Platelet Count } \\
\text { (cells/ul) }\end{array}$} & A & $326 \pm 98 \times 10^{3}$ & \multirow{5}{*}{87.96} & \multirow{5}{*}{0.0001} \\
\hline & $\mathrm{B}$ & $689 \pm 178 \times 10^{3}$ & & \\
\hline & C & $702 \pm 141 \times 10^{3}$ & & \\
\hline & $\mathrm{D}$ & $518 \pm 124 \times 10^{3}$ & & \\
\hline & $E$ & $529 \pm 101 \times 10^{3}$ & & \\
\hline
\end{tabular}

Group A: Control, Group B: Diagnosed cases of Celiac Disease, Group C: Patients with Celiac-like symptoms, Group D: Type I Diabetes patients with Celiac-like symptoms, Group E: Type I Diabetes patients

with IDA have biopsy-proven CD verified by recent meta-analysis and systematic review." Hemorrhagic cases can be the representing characteristic of $C D$, including cases with extreme malabsorption and coagulation deficits. ${ }^{12}$ The probable rationale of hemorrhagic diathesis is vitamin $\mathrm{K}$ deficiency, while other analysis have also theorized mimicry between tissue transglutaminase and factor XIII. Different studies showed different frequencies of hematological manifestations of $\mathrm{CD}$. $^{13}$

In this study we evaluated the pattern of hematological manifestations among different pediatric Celiac groups i.e.; diagnosed $C D$ vs. suspected $C D$ vs $C D$ TIDM cases. The analyzed parameters were hemoglobin, mean corpuscular volume $(\mathrm{MCV})$, mean corpuscular hemoglobin $(\mathrm{MCH})$, mean corpuscular hemoglobin concentration (MCHC) and platelet count and transferrin levels disturbed in poorly and late diagnosed $C D$ cases. The purpose of the study was to know the prevalence of varied clinical features of $C D$ in children from Sindh. This research may help in differential diagnosis and proper management of celiac disease.

\section{METHODS}

\section{Study setting}

This cross-sectional study was organized after approval of ethical research committee of Institute of Biotechnology and Genetic Engineering, Board of Advance Studies and Research, University of Sindh, Jamshoro, Pakistan. Study duration was January to December 2018. A brief oral and written consent was taken from all the parents/guardians of the subjects in this study.

In total I 75 pediatric patients (age 3-I5 years) diagnosed as the cases of $C D$ through serological or intestinal biopsy, patients having symptoms but undiagnosed for $C D$ and diagnosed cases of TIDM with CD were included in the study. All samples were collected from Liaquat University of Medical and Health Sciences Hospital (LUMHS), Isra University Hospital and Asian Institute of Medical Sciences (AIMS) Hospital, Hyderabad, Pakistan. The experiments were performed in Molecular Biotechnology laboratory at the Institute of
Biotechnology and Genetic Engineering, University of Sindh, Jamshoro and at Isra university laboratory, Hyderabad, Pakistan. The individuals were equally divided into 5 groups $(n=35$ each group); Control (Group A), Diagnosed cases of Celiac Disease (Group B), Patients with Celiac-like symptoms (Group C), TIDM patients with Celiaclike symptoms (Group D) and TIDM patients (Group E).

\section{Blood analysis}

Five (5) $\mathrm{ml}$ of venous blood sample was taken from each patient. The blood collected in EDTA tube was then sent for blood complete picture (CP) report. For all patients the blood $\mathrm{CP}$ was carried out. For complete blood count, automated analyzer (Hitachi Roche, Japan) was used.

\section{Transferrin test}

Total serum transferrin concentration was determined by using Human transferrin receptor kit (by Bioassay Technology Laboratory) and analyzed on ELISA reader (DIAsource 2000, Belgium). This kit follows the sandwich model ELISA.

All the data was collected via detailed questionnaire; to know the history, demographic details clinical features and gluten-free diet status of each patient. Data was analyzed by using SPSS version 2.0.

\section{RESULTS}

The mean age of the study participants $(n=175)$ was $9.5 \pm 1.2$ years. There were II 12 (64\%) male and 63 (36\%) females in this survey. It was observed that $C D$ is diagnosed later and is poorly treated. The only treatment for CD is strict gluten absence from diet. Almost $80 \%$ patients and families were unaware of the concept of gluten free diet, so many of the cases had severe malnutrition. The group $A$ was the diagnosed cases of Celiac either by serological or intestinal biopsy tests. For the celiac-suspected groups including TIDM group, the serological testing (anti-tTG) was carried out.

\section{Red blood cell indices}

The most common and in few cases (I5\%) the only symptom observed was 
TABLE II: TRANSFERRIN LEVELS AMONG DIFFERENT GROUPS ( $\mathbf{N}=175)$

\begin{tabular}{|c|c|c|c|c|}
\hline & Groups & Mean \pm S.D & F-Value & P-Value \\
\hline \multirow{5}{*}{$\begin{array}{l}\text { Transferrin levels } \\
(\mathrm{mg} / \mathrm{dl})\end{array}$} & $\mathrm{A}$ & $271.1 \pm 39.1$ & \multirow{5}{*}{46.98} & \multirow{5}{*}{0.0001} \\
\hline & B & $411.5 \pm 24.8$ & & \\
\hline & C & $387.7 \pm 22.4$ & & \\
\hline & $\mathrm{D}$ & $406.4 \pm 21.4$ & & \\
\hline & $E$ & $368.8 \pm 22.0$ & & \\
\hline
\end{tabular}

Group A: Control, Group B: Diagnosed cases of Celiac Disease, Group C: Patients with Celiac-like symptoms, Group D: Type I Diabetes patients with Celiac-like symptoms. Group E: Type I Diabetes patients

anemia. In the cohort studied for Celiac disease the mean hemoglobin levels in Group B, C and D were 9.1, 9.03 and $8.64 \mathrm{mg} / \mathrm{dl}$ respectively. Whereas the normal hemoglobin levels should be in the range of 12 to $16 \mathrm{mg} / \mathrm{dl}$, as observed in-group $A$ and $E$. Table I shows comparison of RBC indices among different celiac groups. The mean of $\mathrm{MCV}$ and $\mathrm{MCH}$ were significantly lower in all patients groups as compared to control group ( $\mathrm{p}-0.000 \mathrm{I})$. MCHC level was significantly decreased in groups $B$, C and D; while it was found $34.1 \pm 0.6 \mathrm{~g} / \mathrm{dl}$ in control group and $30.2 \pm 0.3 \mathrm{~g} / \mathrm{dl}$ ingroup $E$.

\section{Platelet count}

In many of the cases, secondary thrombocytosis was observed. The mean platelet level was significantly higher $689 \pm 178 \times 10^{3}$ cells $/ \mu \mathrm{L}$ in-group $\mathrm{B}$, in contrast to control group $(\mathrm{p}$ $0.000 \mathrm{I}$ ). Platelet Count was also raised in other groups (Table I). There were six cases with severe thrombocytosis having levels above $\sim 1200 \times 10^{3}$ cells $/ \mu \mathrm{L}$.

\section{Transferrin}

For healthy individuals the range of transferrin should be $170-370 \mathrm{mg} / \mathrm{dl}$, which was observed in the group $A$. For group $B$ the highest transferrin level $(4 I \mathrm{l} .5 \pm 24.8 \mathrm{mg} / \mathrm{dl})$ was observed (Table II). Because majority of patients had severe anemia and were not on strict gluten free diet, the symptoms of celiac were persistent with less recovery. Also for group $C$ the ranges were observed to be on higher end. In participants, suffering from both diabetes and celiac (group D) the transferrin was observed to be $406.4 \mathrm{mg} / \mathrm{dl}$.

\section{DISCUSSION}

Several research over the years have widened the understanding about clinical features of $C D^{14}$. But from typical to atypical Celiac the varied symptoms pose challenges in proper diagnosis of $\mathrm{CD}$. In this cross-sectional study out of I 75 children; males were $64 \%$ and $36 \%$ were females. Studies have observed that $C D$ is more prevalent in females than males; like in other autoimmune disorders. ${ }^{15}$ Another study conducted by Green $\mathrm{PH}$, et al. ${ }^{16}$ on 1612 patients from all United States of America analyzed that the females are more affected (2.9:I).

The celiac children cohort had typical symptoms of disease such as chronic diarrhea, abdominal pain, and fatigue and weight loss. The blood complete picture revealed misbalance in RBC indices and platelet count. The mean hemoglobin level was observed lower among celiac disease patients as compared to healthy controls ( $p$ $0.000 \mathrm{I}$ ). In comparison to our results, study conducted by Chen CM, et al. ${ }^{17}$ reported that occurrence of iron deficiency (ID) (3.7\% infants) and IDA (2.7\% infants) under 6 months of age was observed, also it further amplified to $20.4 \%$ and $6.6 \%$ respectively, in children above six months of age. The healthy group had a higher total iron than ID and IDA groups. Sanseviero MT, et al. ${ }^{18}$ also stated in their findings that $I 56$ patients comprising of (19.8\%) females and $(10.2 \%)$ males had anemia, they also showed symptoms of IDA (2I.62\%), few had thalassemia characteristics without ferric deficiency and the remaining affected with other forms of anemia. About (22.20\%) of the patients had decreased ferritin levels and with border line hemoglobin values.

Among all the groups studied the MCV, $\mathrm{MCH}$ and $\mathrm{MCHC}$ were significantly lower with $p$-value of $0.000 \mathrm{I}$. The main reason behind this is the poor or no absorption of iron from the damaged intestinal walls. Radlovic N, et al. ${ }^{19}$ had reported that in chronic and late diagnosed cases $52 \%$ of the patients were anemic, out of these (72 \%) were microcytic (MCV $<70 \mathrm{fl})$ and remaining were normocytic (MCV 70-87 fl). The authors also reported that they observed iron deficiency along with hypo-ferritinemia in majority of celiac patients.

In this survey the platelet levels were unusually high indicating secondary thrombocytosis with the highest levels observed in all three celiac groups (B, C $\& D)$. There were six cases observed in group $B$ having severe thrombocytosis with levels as high as $1200 \times 10^{3}$ cells $/ \mu$. Similarly in group C, D and E platelet count with mean of $702 \times 10^{3}$ cells $/ \mu \mathrm{l}$, $5 \mid 8 \times 10^{3}$ cells $/ \mu \mathrm{l}$, and $529 \times 10^{3}$ cells $/ \mu \mathrm{l}$, respectively was observed. There are many reports that coincide with our data showing elevation in platelet count. Halfdanarsonetal TR, et al. $^{20}$ has described that in $C D$ patients anemia may follow thrombocytosis. Another study by Dan stated that in majority of Celiac affected children the average platelet count is $\sim 700 \times 10^{3} / \mu \mathrm{l}^{21}$ However, studies show relationship between anemia and thrombocytosis, but the clear mechanisms and cause is still under debate..$^{22}$ In anemic CD children, the erythropoietin is up-regulated. It is interesting to point out that the amino acid sequence of protein erythropoietin is quite similar to that of thrombopoietin and it might be one explanation for the secondary thrombocytosis occurrence. ${ }^{23}$ For healthy individuals the range of transferrin should be $170-370 \mathrm{mg} / \mathrm{dl}$, which was observed in the group A. For group $B$ the highest transferrin level was observed. Because majority of patients had severe anemia and were not on strict gluten free diet due to which symptoms of celiac were persistent with less recovery. Also, for group $C$ the ranges were observed to be on higher end. In participants suffering from both diabetes and celiac: group D the transferrin was observed to be $406.4 \mathrm{mg} / \mathrm{dl}$.

The poorly managed $C D$ cases in all groups had elevated levels of transferrin (Table II). When iron is absent, the transferrin protein levels are raised. Transferrin is an iron-binding glycoprotein that maintains the levels of iron in biofluids. When transferrin levels are higher, there is reciprocal decrease in transferrin iron saturation and corresponding increase in TIBC. ${ }^{24,25}$

The CD children in concurrence with 
TIDM were severely malnourished with life threatening anemia for some cases in our study. After autoimmune thyroiditis, diabetes mellitus type $\mathrm{I}$ is the second common autoimmune disorder in comorbidity to $C D$. Due to mutual sharing of genetic loci in CD and TIDM the chances of acquiring celiac disease are increased than the normal population. ${ }^{26}$ One Pakistani study by Rasheed, et al. from Multan tertiary hospital has reported a list of many genetic disorders in concurrence with CD; among those $\operatorname{TIDM}(8.3 \%)$ being most prominent. ${ }^{27}$ Moreover, most of these cases were observed to be late diagnosis. In addition, association of TIDM, epilepsy and arthritis with CD in Turkish and Dutch cohorts has been published. ${ }^{28}$ The CD- TIDM group $D$ in this survey showed, the mean hemoglobin, MCV, $\mathrm{MCH}$ and $\mathrm{MCHC}$ levels significantly decrease, while platelet count was at higher end. TIDM patients suffer from cardiac, kidney and pancreatic stress which leads to hematologic anomalies and when in conjunction with $C D$ the anemic profile intensifies. ${ }^{29}$

\section{CONCLUSION}

This study emphasizes the need for better awareness about varied clinical symptoms of Celiac, which causes delays in diagnosis. The hematological abnormalities were frequently present in CD children studied. Markers of irondeficiency (RBC indices) and changes in platelet count should be considered to aid in management and diagnosis of celiac disease at clinical settings. Children having other autoimmune disorders like TIDM must also be tested for $C D$, if they are suffering from any of the celiac related symptoms.

\section{REFERENCES}

I. Akhtar S, Ahmed A, Ahmad A, Ali Z, Riaz $M$, Ismail $T$. Iron status of the Pakistani population-current issues and strategies. Asia Pac J Clin Nutr 20I3;22(3):340-7. DOI: 10.6133/ apjen.20I3.22.3.I7.

2. Khatoon S, Ahmed A, Yousaf S. Iron deficiency anemia in pakistan: celiac disease an underlying cause. J Ayub Med Coll Abbottabad 2018;30(3): 372-6.
3. Rwalah M, Kamal N, Hijazeen R, Ghanma A, Alzeben Z, D'ajeh R. Hematological findings among Jordanian children with celiac disease at presentation: a retrospective analytical study. J Royal Med Serv 2014; I02(I326): I-6. DOI: 10.128 | $6 / 0008059$.

4. Albrady A, Alharbi F, Almutairi A, Alhujaylan M, Almutiri N, Aljarallah B. Clinical Profile of Celiac Disease: Patient Epidemiological Prospective. Ann Med Health Sci Res 20 I 8;8.

5. Riddle MS, Murray JA, Porter CK. The incidence and risk of celiac disease in a healthy US adult population. Am J Gastroenterol 2012; 107 (8):I248-55. DOI: I0.1038/ajg. 2012.130 .

6. Jamali AA, Shaikh B, Jamali AA, Jamali GM, Kanhar IA, Tanwani BM. Chronic diarreha: frequency of celiac disease in childerns at teatiary care hospital. Indo Am J Pharmaceutical Sci 20 I8;5(4):2252-9.

7. Rashid M, Khan AG. Celiac disease in Pakistan: challenges and opportunities. J Ayub Med Coll Abbottabad 2009;2I(3): I-2.

8. Green PH. Where are all those patients with Celiac disease? Am J Gastroenterol 2007 Jul;।02(7): |46I-3. DOI: I0. I I | I/j. I572-024 | 2007.0II67.x.

9. Al-Toma A, Volta U, Auricchio R, Castillejo G, Sanders DS, Cellier C, et al. European Society for the Study of Coeliac Disease (ESsCD) guideline for coeliac disease and other gluten-related disorders. United European Gastroenterol J 2019 Jun;7(5):583-6I3. DOI: I0.1I77/ $20506406|9844| 25$.

I0. Ludvigsson J, Bai J, Biagi F, Card TR, Ciacci C, Ciclitira PJ, et al. BSG Coeliac Disease Guidelines Development Group; British Society of Gastroenterology. Diagnosis and management of adultcoeliacdisease: guidelines from the British Society of Gastroenterology. Gut 2014;63(8): $1210-28$. DOI: I0. I | 36/gutjnl-20 I3-306578.

I I. Farrell RJ, Kelly CP. Celiac sprue. N Engl J Med 2002;346(3): I 80-8. DOI: I0.1056/NEJMra0 I 0852.
12. Fisgin T, Yarali N, Duru F, Usta B, Kara A. Hematologic manifestation of childhood celiac disease. Acta Haematol 2004; I I I (4):2 I I-4. DOI: 10.1159/000077568.

13. Balaban DV, Popp A, lonita Radu F, jinga M. Hematologic Manifestations in Celiac DiseaseA Practical Review. Medicina (Kaunas) 2019;55(7):373. DOI: 10.3390/medicina55070373.

14. Mäki M, Mustalahti K, Kokkonen J, Kulmala P, Haapalahti M, Karttunen $\mathrm{T}$, et al. Prevalence of celiac disease among children in Finland. N Engl J Med 2003 Jun 19;348(25):25। 7-24. DOI: I0. I056/NEJMoa02 I 687.

15. Rolfsen M, Lodhia N. Atypical Presentation of Celiac Disease: 2182. Am J Gastroenterol 2016; II I:pS1043.

16. Green PHR, Stavropoulos SN, Panagi SG, Goldstein SL, Mcmahon DJ, Absan H, et al. Characteristics of adult celiac disease in the USA: results of a national survey. Am J Gastroenterol 200I Jan;96(I):1263I. DOI: I0.IIII/j.I572-024I. 2001.03462.x.

17. Chen CM, Mu SC, Shih CK, Chen YL, Tsai LY, Kuo YT, et al. Iron status of infants in the first year of life in northern Taiwan. Nutrients 2020;12(I):I39. DOI: 10.3390/nu 12010139.

18. Sanseviero MT, Mazza GA, Pullano $M N$, Oliveiro AC, Altomare $F$, Pedrelli $L$, et al. Iron deficiency anemia in newly diagnosed celiac disease in children. Minerva Pediatr 2016;68(I):I-4.

19. Radlovic N, Lekovic Z, Mladenovic $M$, Radlovic V, Vuletic B, Ducic S, et al. Frequency, severity and type of anemia in children with classical celiac disease. Srp Arh Celok Lek 20।9; |47(3-4): I89-92. DOI: I0.2298/SARHI8I 20302 IR.

20. Halfdanarson TR, Litzow MR, Murray JA. Hematologic manifestations of celiac disease. Blood 2007;109(2): 4I2-2I. DOI: I0.I I82/blood-200607-03।I04.

2I. DAN K. Thrombocytosis in iron deficiency anemia. Intern Med 
2005;44(10): 1025-6.

22. Carroccio A, Giannitrapani L, Di Prima L, lannitto E, Montalto G, Notarbartolo A. Extreme thrombocytosis as a sign of coeliac disease in the elderly: case report. Eur J Gastroenterol Hepatol 2002 Aug; 14(8):897-900. DOI: 10.1097/ 00042737-200208000-00017.

23. Fasano A. Celiac disease--how to handle a clinical chameleon. N Engl J Med 2003 Jun 19;348(25):2568-70. DOI: 10.1056/NEJMe030050.

24. Kawabata H. Transferrin and transferrin receptors update. Free Radic Biol Med 2019 Mar;133:4654. DOI: 10.1016/j.freeradbiomed. 2018.06 .037$.

25. Litchford MD. Nutritional issues in the patient with diabetes and foot ulcers. In Levin and O'Neal's The Diabetic Foot: Elsevier; 2008:199217.

26. Spijkerman M, Tan IL, Kolkman JJ, Withoff S, Wijmenga C, Visschedijk $M C$,et al. A large variety of clinical features and concomitant disorders in celiac diseaseA cohort study in the Netherlands. Dig Liver Dis 2016
May;48(5):499-505. DOI: I0.10I6/ j.dld.2016.01.006.

27. Rasheed J, Khan T, Khalid M, Zafar F. celiac disease: a medley of clinical features a tertiary care hospital experience. Prof Med J 2018;25(5): p669-75.

28. Ipikay S, Hizli P, Yilmaz K. Prevalence of celiac disease in Turkish children with idiopathic epilepsy. Iran J Pediatr 20। 4;24(3):280-4.

29.Jansson L. The regulation of pancreatic islet blood flow. Diabetes Metab Rev 1994;10(4):407-16. DOI: 10.1002/dmr.5610100405.

\section{AUTHOR'S CONTRIBUTION}

Following authors have made substantial contributions to the manuscript as under:

KS: Conception and study design, acquisition of data, drafting the manuscript, critical review, approval of final version to be published

MR: Acquisition of data, drafting the manuscript, approval of final version to be published

AB: Analysis and interpretation of data, drafting the manuscript, approval of final version to be published

AAU: Acquisition, analysis and interpretation of data, critical review, approval of final version to be published

Authors agree to be accountable for all aspects of the work in ensuring that questions related to the accuracy or integrity of any part of the work are appropriately investigated and resolved.

\begin{tabular}{|c|}
\hline CONFLICT OF INTEREST \\
Authors declared no conflict of interest \\
GRANT SUPPORT AND FINANCIAL DISCLOSURE \\
Authors have declared no specific grant for this research from any \\
funding agency in the public, commercial or not-for-profit sectors
\end{tabular}

\section{DATA SHARING STATEMENT}

The data that support the findings of this study are available from the corresponding author upon reasonable request.

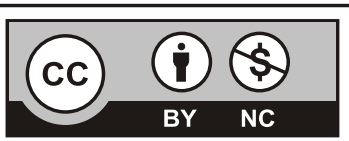

This is an Open Access article distributed under the terms of the Creative Commons Attribution-Non Commercial 2.0 Generic License.

KMUJ web address: www.kmuj.kmu.edu.pk

Email address: kmuj@kmu.edu.pk 